\title{
DECISION SUPPORT IN SOFTWARE SUPPORTED NEGOTIATIONS
}

\author{
Tomasz Wachowicz \\ University of Economics in Katowice, Department of Operations Research, \\ ul. Bogucicka 14, 40-227 Katowice, Poland \\ E-mail: tomasz.wachowicz@ue.katowice.pl
}

Received 23 November 2009; accepted 20 August 2010

\begin{abstract}
In this paper we consider the idea of negotiations conducted by means of the software support tools. We present the advantages of the negotiation support systems discussing their different functions and typologies focusing later on the possibilities of decision support they can give to the negotiating parties in all negotiation phases. After presenting the most popular solutions we introduce also two of our own procedures that can be applied in the pre-negotiation phase for eliciting negotiators' preferences and building the offers' scoring systems for the parties. The first one is based on the Hammond, Keeney and Raiffa's procedure of even swaps, while the second derives from the Roy's ELECTRE-TRI. Both of them can be easily applied as the analytic engines in electronic negotiation systems replacing the classical additive scoring systems. We discuss also the issue of using different scoring systems in the successive negotiation phases.
\end{abstract}

Keywords: negotiations, negotiation support systems, decision analysis, multiple criteria decision making, even swaps, ELECTRE-TRI.

Reference to this paper should be made as follows: Wachowicz, T. 2010. Decision Support in Software Supported Negotiations, Journal of Business Economics and Management 11(4): 576-597.

\section{Introduction}

Negotiation is an everyday task. Except for simple and typical situations like discussing the task shared in a family (i.e. walking the dog, cleaning the apartment, etc.) influencing someone to change their mind or dividing the scarce resources, it includes also the complex deliberations between the companies, political parties or nations. We can describe negotiation situation as the problem of making decision about parties' interdependent goals and objectives (Lewicki et al. 1999). Moreover, the parties are committed to peaceful means of solving the problem and there is no clear or established method of making the decision. Usually, while thinking of the negotiation we consider a regular face-to-face meeting where the parties are sitting at the negotiation table and solving the problem using some advisors, analysts, facilitators or mediators. But we live in the time of technological explosion, and nowadays it influences nearly all the activities 
undertaken by humans, including negotiation. Negotiations are consequently being conducted by means of the electronic media, starting with simple phone calls, through the videoconferences, online chatting, with the use of software negotiation support system (NSS), ending with the electronic negotiation system (ENS) - a software that employs Internet technologies and is deployed on the web for the purpose of facilitating, organizing, supporting and/or automating activities undertaken by the negotiators and/or the third party (Kersten and Lai 2007). More and more people and organizations are deciding to negotiate electronically, since it saves time and money and allows to develop and maintain the business contacts regardless of the distance of time and space between the counterparts. Therefore, the negotiation support tools are still being developed to make the negotiation process more fluent and bring negotiators closer to the most satisfying agreement. Usually, these systems implement the formal models deriving from operational research and decision science that are used to help negotiators define negotiation space, evaluate offers and determine efficient solutions. There are a lot of NSSs and ENSs that have been used for simulating, training and teaching negotiations or for research purposes like INSPIRE (Kersten and Noronha 1999), Negoisst (Schoop et al. 2003), NeGoGo (Lai et al. 2007) or NegoCalc (Wachowicz 2008). Lots of theoretical and practical solutions for electronic negotiation support are also proposed in the literature, that focuse on both the methodological and applicational aspects of electronic negotiations (see Stroebel and Weinhardt 2003; Urbanavičienè et al. 2009a, b). Unfortunately, there are only a few examples of using the formal models and systems in the large and complex real-world negotiations of business or political nature. One of them was introducing the Deep Ocean Mining Model into the United Nations' UNCLOS III negotiations (Sebenius 1984) concerning the rights to exploit the deep sea. It allowed to make a consensus between the developed and developing countries according to the profits sharing. Another system, developed by International Institute for Applied System Analysis, is RAINS (Hordijk 1991), which was used in the international negotiations between the European countries on the air pollution limits. Some other systems are still being developed to support real-world problems like Familly_Winner (Bellucci and Zeleznikow 2005) designed on Victoria University, Australia, for supporting divorcing disputes or Smartsettle (Thiessen and Soberg 2003), which is now being adapted to support negotiations between First Nations and the Government of Alberta Province in Canada (Thiessen and Shakun 2009).

In this paper we describe the negotiation process supported by NSS and ENS with considering all the subsequent negotiation phases and activities required within each phase and the support that can be given by the software systems. In the first section we discuss the fundamental elements of negotiation process and analyze the different types of NSSs that can be used for supporting different aspects of negotiation process. In the successive sections we consider the subsequent negotiation phases. Considering the pre-negotiation phase we focus on negotiators' preference elicitation and process of building offers' scoring systems that require formal modeling and usually implement an additive scoring system. We also propose two alternative solutions that can be introduced instead of classical additive scoring system. Next we describe the support that 
can be given within the actual negotiation phase for exchanging the messages and offers and analyzing the negotiation progress. Afterwards, we analyze the post-negotiation mechanisms that can be introduced by NSS to help negotiators evaluate the compromise and find better solutions.

\section{Negotiations and negotiation software support}

\subsection{Negotiation process}

In vast majority of situations the basis of negotiation is some form of conflict. But negotiation and conflict are not the same thing. As far as conflict is the perception of differences of interest among people, negotiation is a decision making process in which two or many people make joint decision about the allocation of scarce resources (Thompson 1998). Since we perceive negotiation as a decision making process we need to be aware of multitude tasks the parties must accomplish to obtain the satisfying solution. Negotiators need to understand the essence of the conflict (i.e. to diagnose the negotiation problem), gather all information required (e.g. about the problem, parties, possible solutions) and process it to manage the negotiation process well (e.g. analyze the counterpart's personality, select negotiation strategies, etc.). Negotiation thus is a very complex activity, which requires from the parties many skills of the behavioral and analytical nature to cope with different problems that can appear during the negotiation process. This process in not uniform, and depending on the stage of the conflict it may require different tasks to perform or problems to solve. There are many proposals of dividing the negotiation process into separate phases (Douglas 1962; Morley and Stephenson 1977). Some of them are quite general, like a six-phase model of Greenhalgh (2001) including preparing, relation building, information gathering, information using, submitting offers, closing and implementing agreement; others are specific to negotiation problems or context, like Four-Phase Model of Hostage Negotiation (Madrigal et al. 2009) that consists of establishing initial dialogue, building rapport, influencing, and Surrender; or a five phases model for negotiating transactions (Tafreschi et al. 2008) distinguishing the information, intention, agreement, execution and service phases. Here we will focus on a very general and straightforward categorization that allows to distinguish three main negotiation phases (Gulliver 1979): pre-negotiation phase, actual negotiation phase and post-negotiation phase.

\subsubsection{Pre-negotiation phase}

Pre-negotiation phase is in fact the preparation for negotiation. Preparing itself consists of some subsequent steps that should lead to a plan of action. The first step of prenegotiation phase is called the ideas stage (Scott 1999), which aim is to review the area of negotiation and the other party. Negotiators should gather all the data and facts describing the present situation between the parties and the essence of conflict. Within the second stage - analysis stage - the data is processed. Parties should identify the strengths and weaknesses of both their own and their counterparts. The goals, intentions, positions, expectations, aspiration and reservation levels and BATNAs of the parties should also be identified. It will lead to the construction of negotiation space, identification of possible alternatives and determination of the zone of possible agreement (Raiffa 
1982). Then in the last stage - organizing the meeting - the negotiators, facilitators and analysts are chosen, the negotiation place and agenda are also prepared. These three stages lead to formulating a direct plan, linking the overall goals with operational tactics which we call a negotiation strategy (Kuhn 1999).

\subsubsection{Actual negotiation phase}

This negotiation phase includes the main talks, offers exchange, making concessions and all the verbal and non-verbal endeavors that parties use to achieve a compromise (see Thompson 1998). This is a sequential process within which we can distinguish five different stages (elements). The first stage is the partner inquiry, which is necessary to find out the true intentions, emotions and position of a counterpart. The next, called mutual influencing, consists in revealing negotiators' views and emotions and is strongly connected with the third element - negotiation maneuvers - which includes all the specific tactics and techniques, both constructive and destructive ones, that are to move negotiators towards the aspired agreement (see Aaronson 1989). These three stages can be repeated iteratively but then stabilizing is required, which will lead the negotiators to the stage of reaching agreement that consists in exchanging the proposals for the final compromise. This entire process starting from the first offer and ending with the mutual agreement is also known as a negotiation dance (Raiffa 1982).

\subsubsection{Post-negotiation phase}

The last negotiation phase begins with the agreement concluding, which effects in writing an official contract and its execution (Lewicki et al. 2004). But this phase extends also to some other tasks, usually realized by the third party - facilitators or mediators, like analyzing the final compromise and looking for the gains that are left on the negotiation table. It is often conducted by means of formal models that help negotiators to evaluate the compromise and, using some elements of mathematical programming, find the effective solutions that dominate the current compromise. It is also the time for conclusions and summarizing the lessons learned that negotiators make use of during the future negotiations.

\subsection{Negotiation support in the software negotiation system}

The software systems may support different tasks at different stages of negotiation process. They can also act as a supportive tool for one negotiator only or have implemented the procedures to support all of them, including the third party (i.e. facilitator or mediator). What is more, they can be either passive tools gathering and visualizing data or can act actively by processing the data, doing calculations, making simulations or suggesting some solutions. We will now focus on the ways of support that negotiation support systems may offer and present some categorization of such systems.

\subsubsection{Support for negotiation phases and parties}

Deriving form the three-phase negotiation model presented in the previous section and taking into account the parties involved in the negotiation process we can categorize negotiation support systems into four types (Kersten and Lai 2007): 
1. Planning and preparation systems used mainly in the pre-negotiation phase. They are designed to support a single negotiator in analyzing private and public information about the negotiation problem and context. They allow to build and evaluate the alternatives applying some scoring methods (e.g. utility based ones). They also support negotiator in formulating their negotiation strategies and tactics that they can apply later in the actual negotiation phase.

2. Assessment systems used within all negotiation phases and support single party. They help in constructing offers, analyzing counter-offers and propose some alternative solutions. They allow to track negotiation progress by analyzing the concession paths.

3. Intervention systems designed to support mediators or arbitrators in all the tasks they are supposed to undertake during the whole negotiation process.

4. Process systems designed for supporting simultaneously all the negotiators. They act according to selected negotiation protocol and impose on negotiators specific organization of the negotiation process, including communication procedures, mechanisms for exchanging offers, etc. Usually they support all negotiation phases.

As we see NSSs can support different phases and actors of negotiation process but, simultaneously, it is also very important how they give this support. The negotiator's satisfaction from using the supporting system is significantly different if the system helps only to present or organize the data or if it offers advanced analytic mechanisms that allow him to act as an advisor or facilitator. Therefore we can consider NSSs taking into account the type of activity they offer.

The general scheme of support the NSS may offer to all the parties involved in the negotiation process is presented in a form of high level use case diagram in Fig. 1.

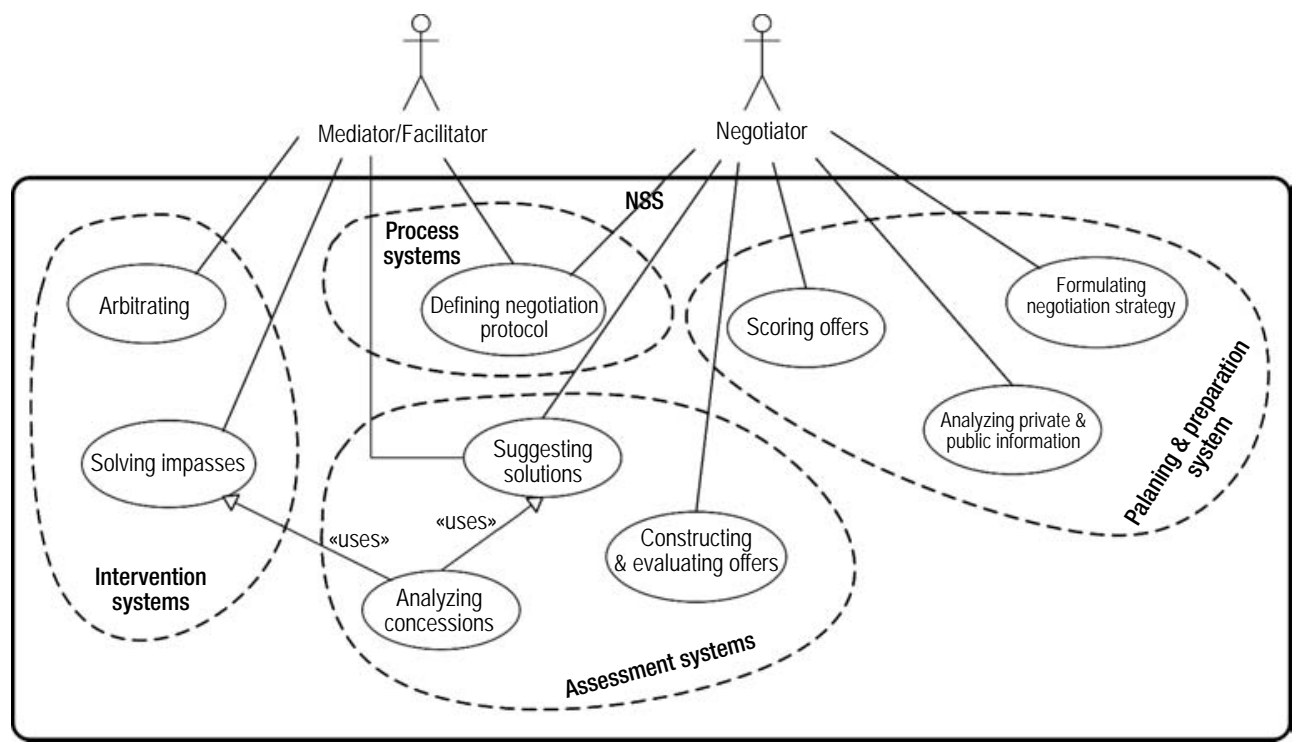

Fig. 1. NSSs and their functions 


\subsubsection{Activity of NSSs}

Taking into account the scale of participation of supporting systems in the negotiation process, the three following types of system can be distinguished (Kersten 2005):

1. Passive systems require users to control over their actions. If used for communication purposes they are simple messengers providing users with mechanisms for conducting the talks. If used for calculation they support negotiators in solving mathematical formulas required to compare the negotiation offers. They also help to display data on graphs or maps. These systems do not verify requirements and assumptions defined by users and expect all the data required to be provided by negotiators.

2. Active facilitation-mediation systems support the whole decision making process in negotiations, starting with problem definition and structuring, and ending with producing the final results in the form of offers that can be suggested as the agreement proposals. They support also concession-making process, and the final assessment of the agreement. The models implemented in these systems take into consideration simultaneously the problem, the negotiators and the process.

3. Pro-active intervention-mediation systems except for playing the role of active facilitation-mediation systems they also intervene in the process by suggesting to the parties some alternative solutions and coordinating their activities. They can monitor the concession path and stimulate the parties to act in the way that will bring them closer to the agreement.

\subsubsection{Roles of NSSs}

We know the different scale of support NSSs give in the successive negotiation phases and the degree of their participation in the negotiation process. The mix of these elements determines in fact the role NSS plays in the negotiations as a third party. We usually distinguish three major roles the third party can play in negotiation, which is a mediator, facilitator and analyst (expert). Therefore analyzing the role NSS plays in the negotiation process we can distinguish three types of negotiations (Kersten and Lai 2007):

1. Computer-facilitated negotiations use software with communication and coordination components implemented only. The technology used do not affect the content of communications therefore the decision and concession making process depends only on the skills of the negotiators. In terms of decision support the system acts passively, however it can inform negotiators of the current stage of talks (e.g. send emails informing of new compromise proposals prepared by counterpart in the system).

2. Computer-supported negotiations use software that can provide negotiators with the information they would not be able to obtain otherwise. This software affects the negotiation process and parties by organizing the negotiation activities and proposing individual mechanisms for analyzing the data and understanding the problem better, like simulation tool or preference elicitation engines. 
3. Computer-mediated negotiations use software that helps parties to achieve an agreement. This software not only supports individual tasks of negotiators but also their cognitive efforts. It tries to identify the potential conflicts by analyzing the moves of counterparts and redirects them by proposing them the concession and suggests the alternative compromises.

\section{Pre-negotiation phase support}

Having discussed the negotiation process and the general way of its support that can be given by software systems we will focus now on the details of decision support in successive negotiation phases. The decision support given by NSSs within the prenegotiation phase focuses mainly on the negotiators' preference elicitation and building the scoring system for offers evaluation. All the formal models required for such a support derive from the negotiation analysis (Young 1991; Raiffa 1982; Raiffa et al. 2002) which is a huge and modern trend within the decision science. The common idea of these models is to define the negotiation outcome quantitatively and use some methods from game theory and multiple attribute decision making to evaluate the implication of the potential solutions and find the efficient, fair or compromising agreement (Luce and Raiffa 1957; Keeney and Raiffa 1976; Brams 1990; Zeckhauser et al. 1996; Hammond et al. 2002). We will discuss below a very popular MCDM model - the additive scoring model - that is usually applied in computer-supported negotiation to develop an assessment capabilities of NSSs.

\subsection{Additive scoring systems}

Additive scoring system is commonly used to evaluate negotiation offers in multi-issue negotiations. The fundamentals of this scoring method can be found in works of Keeney and Raiffa (Keeney and Raiffa 1976; Raiffa 1982; Keeney and Raiffa 1991). Usually this scoring is applied to discrete decision making problems, however it can be easily adapted to the continuous problems by introducing linear or nonlinear interpolation between the scores. We will assume then, that there is a negotiation problem and negotiation space defined in the form of the set of issues $I$ and finite sets of options $X_{i}$ (realization levels of each issue $i=1, \ldots,|I|$ ). Each negotiation offer, perceived as the complete package, can be thus denoted as

$$
a=\left[x_{1}, x_{2}, \ldots, x_{|I|}\right],
$$

where $x_{i}$ is a realization level chosen from the set of feasible options $X_{i}$ for issue $i$.

The main idea of the additive scoring system is to score each option that can comprise the negotiation offer by using an artificial criterion like utility or desirability. The process of scoring offers and building the final ranking of them requires four stage analysis: 1. Assigning weights to the negotiation issues by distributing a certain number of scoring points among all of them.

In the first step negotiator declares the importance of issues. He assigns the weights $w_{i}$ for each issue $i=1, \ldots,|I|$, such as:

$$
\sum_{i} w_{i}=P
$$

where $P$ is the total pool of scoring points established by the negotiator. 
To make the interpretation of scores easier it is recommended to use a pool of 100 scoring points, which allows then to explain the global score of offers as percentage of satisfaction (Kersten and Noronha 1999).

2. Assigning scores to each option within each issue, using the pool of scores assigned to the issue.

Negotiator distributes the scoring points according to his subjective perception of the quality of each option and following the rule that the most preferred the option is, the higher score it receives. He assigns a certain number of scoring points to each option $x_{i}^{k} \in X_{i}$ up to the limit defined by the weight of this option:

$$
u\left(x_{i}^{k}\right) \in\left[0, w_{i}\right]
$$

for $k=1, \ldots,\left|X_{i}\right|$ i $i=1, \ldots,|I|$,

where the least preferred option $x_{i}^{\text {least }}$ receives the score of 0 points and the most preferred one $x_{i}^{\text {most }}$ - the score of $w_{i}$.

3. Determining the global scores of offers by adding up the scores of options that comprise them.

Each offer $a^{m} \in A$ ( $A$ - set of feasible offers, built with the combination of all possible options defined for all negotiation issues) receives the score:

$$
u\left(a^{m}\right)=\sum_{i} u\left(x_{i}^{a^{m}}\right),
$$

for $m=1, \ldots,|A|$ i $i=1, \ldots,|I|$, where $x_{i}^{a^{m}}$ is the option value for the issue $i$ that builds the offer $a^{m}$.

\section{Building the ranking of offers according to descending global scores.}

Having completed all four steps of the above procedure we obtain a full scoring system of the feasible offers. Negotiators can use this system to compare proposals submitted by their counterparts and analyze the differences between quality (satisfaction rate) of the subsequent offers (that have the interval scale interpretation). Negotiators can also observe how the score is determined while the options are added or changed within the offer they prepare. The system allows also to follow the negotiation progress by analyzing the concession paths - the shape of the graph built with scores of successive offers submitted both by the negotiator himself and his counterpart. Such a solution is commonly applied in the NSS, for example in Inspire (Kersten and Noronha 1999), Smartsettle (Thiessen and Soberg 2003) or Negoisst (Schoop et al. 2003). An example of scoring negotiation offers with additive scoring system in Inspire ENS is shown in Fig. 2.

But there are some disadvantages of additive scoring system. The first is that the scores negotiators use need to be simply assigned to the issues and options instead of determining them - deriving from their preferences defined verbally (Saaty 2001). What is more, operating with utility or desirability scores requires from negotiators some mathematical skills and at least a basic knowledge of decision theory, otherwise the global scores may be misinterpreted or, which is worse, the whole scoring system may not reflect the true preferences of negotiator. The second problem is that negotiators do not have to assume full compensation between the issues. Negotiation experiments conducted by 


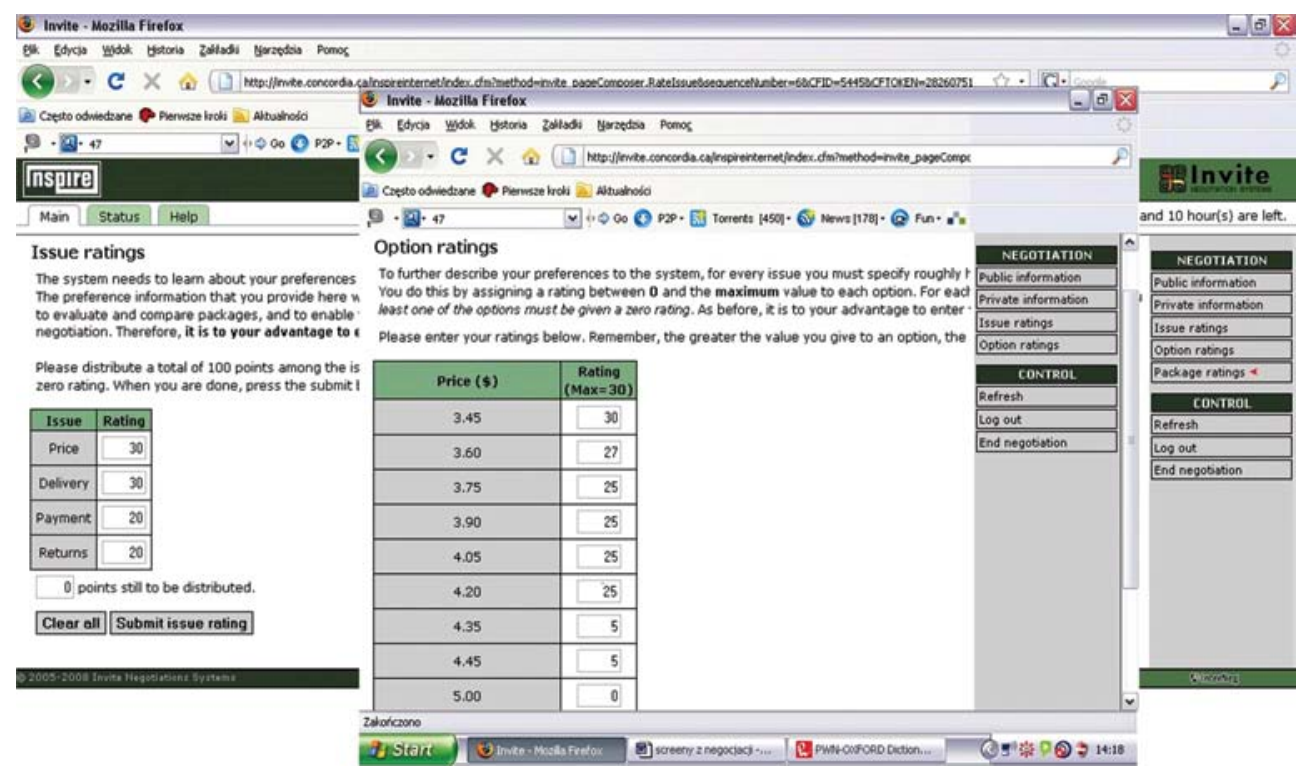

Fig. 2. Additive scoring system in ENS Inspire

Wachowicz and Kersten (2009) show that negotiators very often reject some alternative solutions proposed by ENS despite they result in the higher score than the current negotiation agreement. It happens because these alternative solutions do not meet the minimal accepted levels for one or more issues. Therefore some alternative solutions are proposed based, for instance, on AHP (Mustajoki and Hamalainen 2000), outranking methods (Wachowicz and Wieszała 2009; Ulubeyli and Kazaz 2009) or verbal analysis (Ustinovichius et al. 2009).

We also decided to develop alternative methods for scoring negotiation offers that will try to overcome some of the problems mentioned above.

\subsection{Even swaps based scoring system}

The first method is based on the straightforward decision making model called even swaps (Hammond et al. 1998). This method has the same mathematical foundations as the additive scoring system, but differs in the philosophy of assigning the scores. It derives from the concept of vector domination assuming that each dominated alternative can be eliminated from the decision process, since it cannot be recommended to the decision maker as the most satisfying one. Furthermore it emphasizes that if all the alternatives result in equal consequences for any criterion, this criterion can be ignored in the decision making process as well (eliminated). Then, the even-swap method tries to adjust the consequences of all considered alternatives to make them equivalent in terms of a given objective, which requires increasing the value of one alternative in terms of one objective while decreasing its value by the equivalent amount in terms 
of another objective. The equivalent amounts are defined subjectively by the decision maker and reflect the structure of his preferences. After such an adjustment the considered objective can be eliminated and domination analysis can be conducted once again with respect to the rest of the objectives.

The process of the objectives elimination is repeated until the decision maker is able to find the best decision (the one that dominates over all the others) or the decision making problem is reduced (by eliminating the criteria) to the single criterion decision making problem.

Let us consider a simple problem of choosing between two alternatives (dwelling houses under construction) that differ in consequences for two criteria: price and building time (Table 1).

Table 1. Alternatives under consideration

\begin{tabular}{lll}
\hline \multirow{2}{*}{ Criteria } & Alternatives \\
\cline { 2 - 3 } & House 1 & House 2 \\
\hline Price (in thousands of \$) & 400 & 370 \\
\hline Building time (in months) & 18 & 20 \\
\hline
\end{tabular}

Comparing these two houses we see that House 2 is cheaper but with longer building time than House 1 (investor wants to minimize both the criteria). No vector domination occurs. Investor needs to conduct then the even-swap analysis between two criteria. According to the procedure he will try to adjust the consequences of these two alternatives to become equal in terms of building time - say, both to be realized within 18 months. House 1 is going to be built within this time, but House 2 not. Investor needs to declare thus an equivalent amount (in terms of thousands of dollars) that will describe what the costs of shortening the building time form 20 to 18 months are. Let us assume that he evaluates the difference as $\$ 15,000$ price equivalent. This amount may reflect some objective costs that decision maker needs to pay for waiting two moths longer for a new house, but also all the subjective and "non-measurable” costs (e.g. the costs of two months longer irritation for an annoying neighbor that lives next door and plays piano until midnight everyday) may (and should) be taken into consideration as well. Now, the equivalent amount can be added to the actual price of House 2 and Table 1 can be rewritten to Table 2 .

Table 2. Alternatives after even-swap analysis

\begin{tabular}{lll}
\hline Criteria & Alternatives \\
\cline { 2 - 3 } & House 1 & House 2 \\
\hline Price (in thousands of \$) & 400 & 370385 \\
\hline Building time (in months) & 18 & 2018 \\
\hline
\end{tabular}


Since both alternatives result in the same value for criterion "building time", it can be eliminated from the decision making problem. After this elimination investor considers between these two alternatives analyzing only the criterion of price, therefore House 2 will be selected as the most preferable solution, since it is cheaper than House 1.

The even-swap method can be easily applied for building the negotiation offers' scoring system. All the modifications required were previously described in details by Wachowicz (2007). The modified procedure requires four step analysis:

1. Defining of the base issue. Base issue is used as a global score for the offers evaluation (like utility payoff in additive scoring system). It is chosen from the set of all negotiation issues that parties agreed to negotiate. It is recommended to choose the quantitative issue as the base, which will make the interpretation of the global scores much easier (it is easier to understand the difference between two prices: $\$ 200$ and \$250, than to understand the difference between two verbal descriptions: interesting and very interesting).

2. Defining the base options for all issues. Making all the offers equal for one particular issue requires selecting the base option as a common result for all the offers. It is recommended to use the best option (i.e. the one that satisfied each issue the most) as a base. The equivalent amount defined then for other options may be interpreted as the cost of upgrading the offer's consequence to the best possible resolution.

3. Assigning the equivalent amounts for options within issues. For each issue separately the negotiator needs to compare all the options with the base option and define the equivalent amount for the differences between them (the base option receives the equivalent amount of 0 ). These equivalent amounts for the quantitative base issue are calculated automatically as the differences between the actual values of the options.

4. It is allowed to conduct such a within-issue analysis because the even-swap method employs an additive aggregation of the scores, which means it assumes that the score associated with each option of one issue does not depend on the options of other issues (Keeney and Raiffa 1991).

5. Calculating the overall scores of offers by adding the equivalent amounts of options that comprise the offers. Similarly to the additive scoring system the global score of offer is determined by adding up the equivalent amounts defined for options that comprise this offer. The overall scores of the offers are interpreted as the costs of their upgrading to the ideal (best) level.

Even-swap based scoring system was applied in a simple spreadsheet based negotiation support tool called NegoCalc (Wachowicz 2008). The key stages of building the negotiation offers' scoring system in NegoCalc are shown in Fig. 3. First the base issue has been selected as the price, and then, after identification of the best options for all remaining issues (building time and warranty time), the equivalent amounts for even swaps in terms of price have been declared.

The even-swap based scoring system overcomes one disadvantage of additive scoring system. It allows negotiators to operate with the global score that they choose them- 


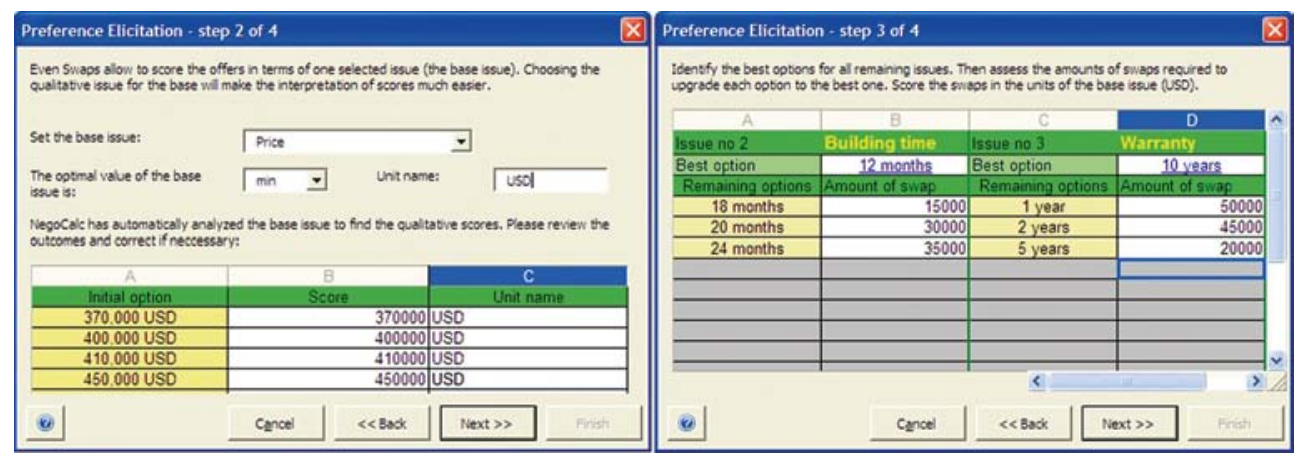

Fig. 3. Building a scoring system of negotiation offers in NegoCalc

selves and the values of which they can interpret and compare easily. For instance, they can select the base issue like price or time and use their units to score offers. However, similarly to additive scoring system, even swaps require assigning swaps instead of determining them and, what is more important, assumes the full compensation for all negotiation issues.

\subsection{Application of calibrated ELECTRE-TRI for scoring negotiation offers}

The recent work of Wachowicz and Wieszała (2009) on alternative pre-negotiation protocols shows that outranking methods (like PROMETHEE) may be applied in negotiation process to evaluate offers. What is interesting, these outranking methods that employ veto thresholds, reject the assumption of compensation, which is concordant with the true negotiation behavior recognized in the research of Wachowicz and Kersten (2009). But on the other hand PROMETHEE or ELECTRE base on pair-wise comparisons and produce the offers scoring systems very sensitive to any change of the negotiation space. The ranking of offers may change diametrically if new options are added, which is a result of the ranking reversal problem (see De Keyser and Peeters 1996). Therefore we decided to employ one of the sorting method from the ELECTRE family - ELECTRE TRI (Roy and Bouyssou 1993).

ELECTRE TRI allows to classify multi-criteria alternatives into the predefined categories, described by the lower and upper-limit profiles. Let $F$ denote the set of indices of the criteria $g_{1}, g_{2}, \ldots, g_{m}(F=\{1,2, \ldots, m\})$, and $B-$ the set of indices of the profiles defining $p+1$ categories $(B=\{1,2, \ldots, p\})$, where $b_{h}$ is an upper limit of category $C_{h}$ and a lower limit of category $C_{h+1}, h=1,2, \ldots, p$ (Fig. 4). We assume here that decision maker's preferences increase with the value on each criterion.

ELECTRE-TRI classifies alternatives into the category $C_{h+1}$ described by the lower limit $b_{h}$ and the higher limit $b_{h+1}$ by verifying the assertion $a S b_{h}$, interpreted as " $a$ is at least as good as $b_{h}$ ”. To verify this assertion a notion of pseudo-criteria is applied, introducing the preference, indifference and veto thresholds (Roy and Vincke 1984) required for determining the credibility indices $\sigma\left(a S b_{h}\right) \in[0.1]$ of assertion $a S b_{h}$. 


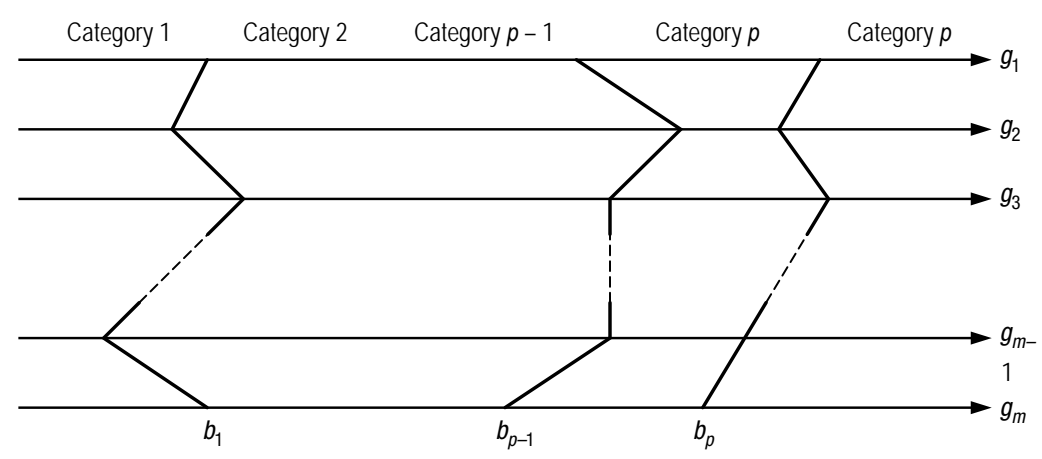

Fig. 4. Definition of categories using limit profiles (Mousseau and Slowinski 1998)

Then the assignment procedure is started, which (in the pessimistic approach) compares $a$ successively to $b_{i}$ for $i=p, p-1, \ldots, 1$ and identifies first profile $b_{h}$, for which $a S b_{h}$. Alternative $a$ is assigned then to the category $C_{h+1}$.

ELECTRE-TRI requires from decision maker the declaration of lots of parameters like profiles, weights, preference, indifference and veto thresholds. It can be troublesome, taking into consideration that these parameters are not so intuitive. Therefore, a few procedures were proposed to estimate the parameters of the ELECTRE-TRI model. One of them, by Mousseau and Slowinski (1998) - let us call it MS model - tries to determine the parameters by analyzing the assignment examples performed by the decision maker. The decision maker is asked to formulate examples of alternatives that he can easily classify to the categories. Basing on these assignments a simple quadratic programming model is constructed, solution of which allows to determine all the parameters except the veto thresholds.

ELECTRE-TRI together with the MS model can be easily applied to build the negotiation offers' scoring system. The only problem that occurs is the precision of offers evaluation. Negotiators can consider the offers from the lower category to be worse than the ones from higher category, but cannot distinguish the differences between the offers classified to the same category. To obtain higher precision of a scoring system a huge number of categories should be defined, but it automatically increases the number of examples negotiator needs to assign in the preliminary stage. We propose an alternative approach that allows for increasing a scoring system's precision, which bases on calibration of the outcomes obtained by solving MS model. The procedure of calibration imposes on negotiator the declaration of satisfaction level that comes from reaching each profile, which we denote $u\left(b_{h}\right)$. Consequently each offer $a$ assigned to category $C_{h+1}$ will result in satisfaction level from the range $\left\langle u\left(b_{h}\right), u\left(b_{h+1}\right)\right\rangle$. If the range is too big to make an effective offers comparison, we propose to divide it into $n$ sub-ranges of equal dimensions, which is equivalent to definition of new sub-categories within the considered category $C_{h+1}$, i.e.: 


$$
\begin{aligned}
& a \rightarrow C_{h+1}^{s} \Rightarrow \\
& u(a) \in\left\langle u\left(b_{h}\right)+(s-1) \frac{u\left(b_{h+1}\right)-u\left(b_{h}\right)}{n},\right. \\
& \left.u\left(b_{h}\right)+s \frac{u\left(b_{h+1}\right)-u\left(b_{h}\right)}{n}\right)
\end{aligned}
$$

where $s=1, \ldots, n$.

Each sub-category is defined by new profiles and the issues' values need to be identified for each of these profiles. They can be determined by linear interpolation between the issues' values of neighboring profiles defining this category. The upper-limit profile of each sub-category but the last (most preferred) one can be determined as:

$$
g_{k}\left(b_{h}\right)=g_{k}\left(b_{h}\right)+s \cdot \frac{g_{k}\left(b_{h+1}\right)-g_{k}\left(b_{h}\right)}{n-1},
$$

for $k=1, \ldots, m$ and $s=1, \ldots, n-1$. The upper limit profile for the sub-category $n$ is $b_{h}$. The whole idea of dividing the ELECTRE-TRI scoring system into sub-categories and calibrating the outcomes in terms of satisfaction levels is presented in Fig. 5.

Having prepared the offers' scoring system as described above, negotiator can evaluate each negotiation offer by assigning it first to the general category, and then to the subcategory within this category. Such an algorithm reduces the number of comparisons that would be far more bigger if the alternative was compared with sub-categories directly.

Let us assume that the negotiator wants to evaluate an offer $a_{1}=[320 ; 10 ; 8]$ within the scoring system shown in Fig. 4, where weights of issues estimated from MS model arew $=[0,35 ; 0,15 ; 0,5]$. He declares also the veto thresholds $p\left(b_{1}\right)=p\left(b_{2}\right)=[10 ; 5 ; 5]$.

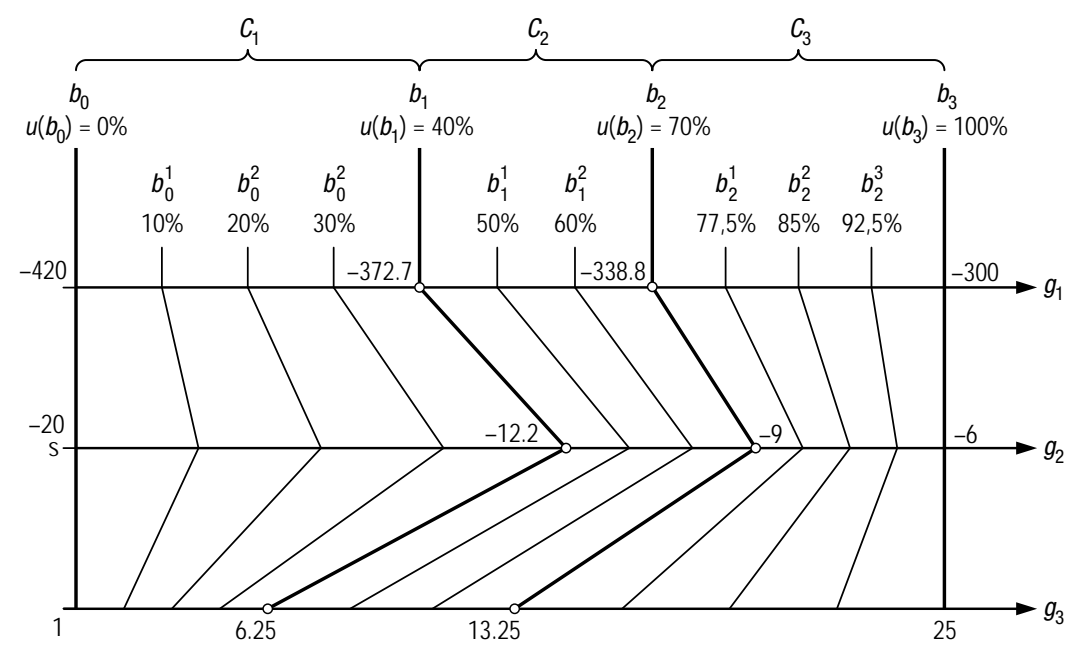

Fig. 5. Sub-categories and satisfaction scores 
According to the pessimistic assigning procedure this offer is compared first with profile $b_{2}$ and later with $b_{1}$, by examining the relation $a_{1} S b_{2}$, i.e. $\sigma\left(a_{1} S b_{2}\right) \geq \lambda$ (we assume $\lambda=0.746$ estimated also from MS model). We obtain $\sigma\left(a_{1} S b_{2}\right)<\lambda$ and $\sigma\left(a_{1} S b_{1}\right)=$ $1>\lambda$, which means $a_{1}$ may be classified to the category $C_{2}$ assuring the satisfaction at level no less than $40 \%$ and no higher than $70 \%$. To make the evaluation more precise we compare now the offer $a_{1}$ with upper-limit profiles $b_{1}^{2}=[350,1 ; 10,08 ; 10,91]$ and $b_{1}^{1}=[361,4 ; 11,14 ; 8,58]$ and obtain the values of credibility indices: $\sigma\left(a_{1} S b_{1}^{2}\right)=0,5$ and $\sigma\left(a_{1} S b_{1}^{1}\right)=0,503$. With the assumed $\lambda=0.746$ we cannot assign $a_{1}$ to any higher category. Therefore $a_{1}$ will be assigned to sub-category $C_{2}^{1}$ that assures the satisfaction at the levels from $40 \%$ to $50 \%$ (Fig. 6).

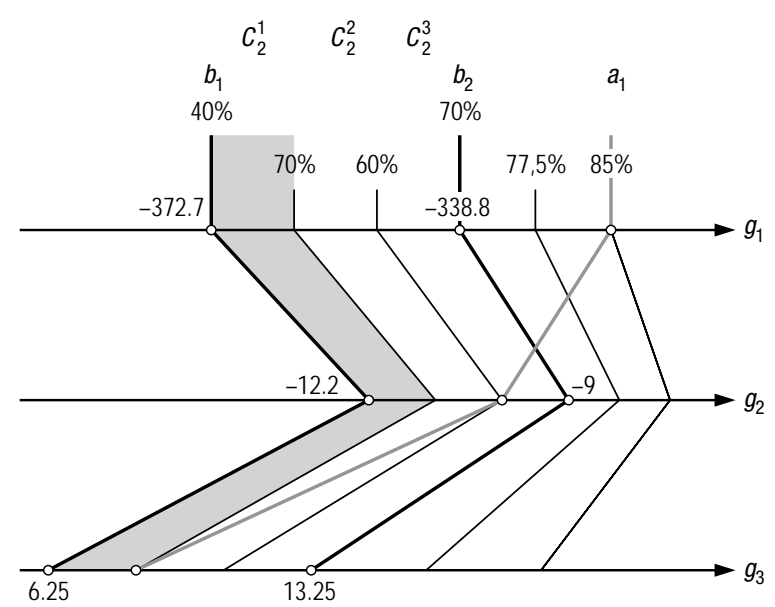

Fig. 6. Assigning the offer to sub-categories

The significant advantage of the calibrated ELECTRE-TRI based scoring system is that it does not need a specification on all feasible options in the pre-negotiation phase, which was required for additive scoring system and even-swap based scoring system. Negotiators need only to agree over negotiation issues, and then define individually their reservation and aspiration levels that determine their negotiation space. And therefore in, the actual negotiation phase they can freely propose as an agreement proposals any offer (even those out of their negotiation space), not only the one based on the predefined options. What is more, negotiators do not need to assign explicitly the scores to issues and options using their decision making skills. All the parameters required for building the scoring system are estimated basing on the assignment examples negotiators declared in the pre-negotiation phase. The idea of scoring negotiation offers with calibrated ELECTRE-TRI scoring system is being tested in the experimental electronic negotiations system. 


\section{Software support for further negotiation phases}

Having the offers' scoring system built, negotiators may take advantage of it in the actual negotiation phase, for following the negotiation progress and analyzing the scale of concessions and also in post-negotiation phase (after achieving agreement), for analyzing the gains left on the table.

\subsection{Actual negotiation phase support}

Both an additive scoring system and even-swap based scoring system can be used in the offer's formulation process for analyzing in details the trade-offs between issues and options. While building the offer (i.e. adding the propositions for reservation levels of successive issues) negotiator can observe how the overall score changes. He can immediately react if the score is lower than his aspiration level by balancing with different combination of options (increasing value of one issue, while decreasing it for another). The process of building negotiation offer in NegoCalc system is presented in Fig. 7.
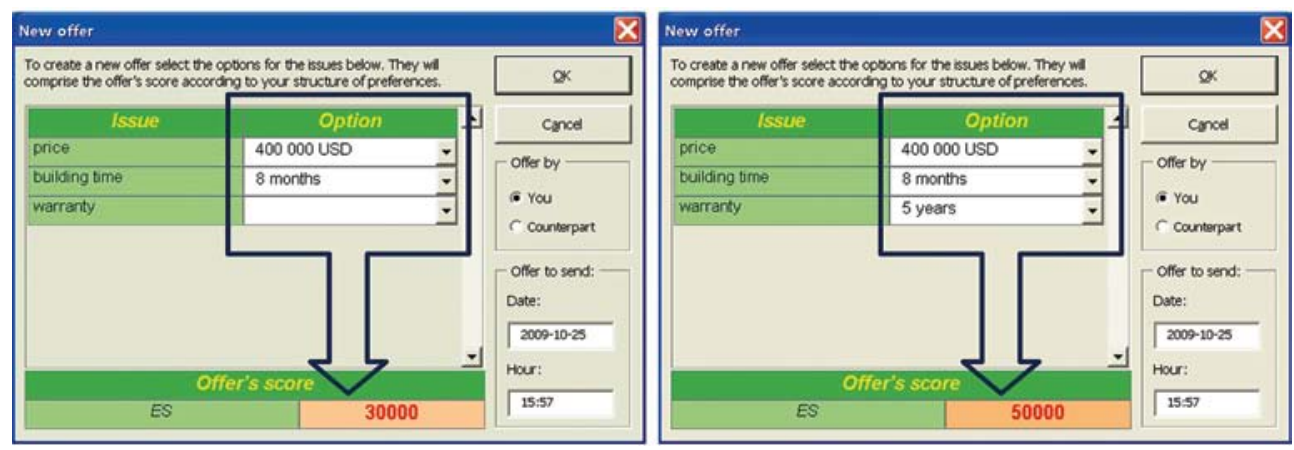

Fig. 7. Analyzing an offer under construction in NegoCalc system

These two scoring systems may be also helpful in graphical illustration of the negotiation progress. A graph depicting the history of offers in the evaluation (utility) space can be used to analyze the dynamics of negotiation - how frequently the offers and counteroffers are submitted and what outcome they produce. It is also very useful in recognizing the scale of successive concessions, basing on which negotiators can conclude on their counterparts negotiation strategy. An example of a history graph displayed in ENS Inspire (Kersten and Noronha 1999) is presented in Fig. 8.

The ELECTRE-TRI based offers' scoring system cannot be used the same way, since it does not operate on the options rating. It does not allow to score any offer until the full package is not created, therefore, negotiators cannot observe in details the direct trade-offs between the different resolution levels of issues. The graph of history cannot be depicted for the offers scored by ELECTRE-TRI either, since the scores are in fact the ranges that correspond to the actual sub-category but not the scalar values. Instead of the classic history graph a simple general map can be drawn showing the pace of concession in terms of moving from one sub-category to another. 


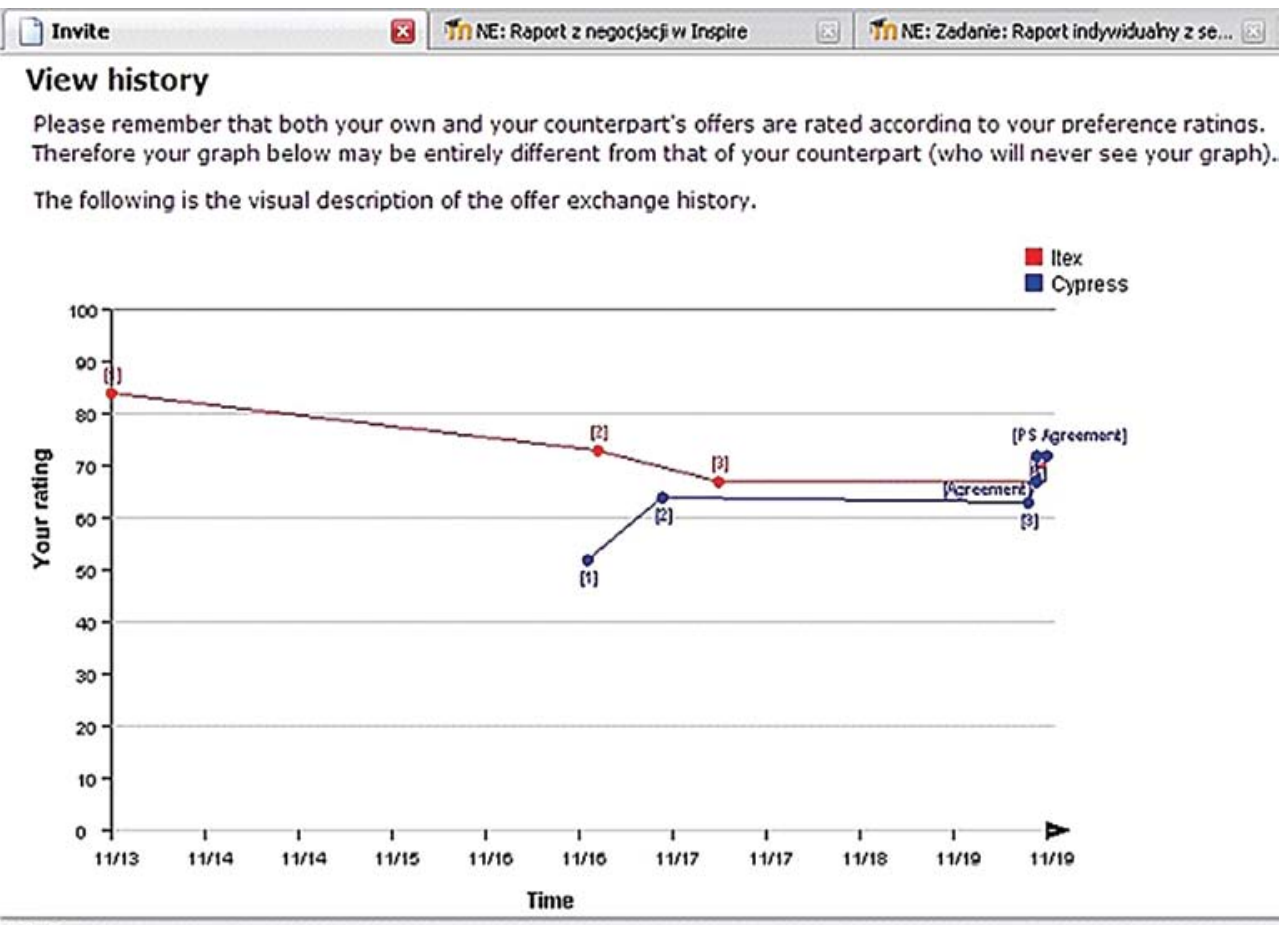

Zakcríczono

Fig. 8. History graph in eNS Inspire

Negotiation support system may also have implemented the optimization engines that allow them to act pro-actively in the actual negotiation phase, like some heuristics or game theory models. These engines may determine the fair solutions and suggest negotiators the alternative offers as the agreement proposals, like in Smartsettle (Thiessen and Soberg 2003).

\subsection{Post-negotiation phase support}

In post-negotiation phase a final contract is signed by the negotiating parties, but before it happens there is time for analyzing the agreement and consider its effectiveness. NSSs can help in analyzing the negotiation space of both the negotiators and finding the better solutions. It is quite a simple task for discrete negotiation problems that are supported by additive scoring systems or even-swap scoring systems. NSSs simply search a finite negotiation space and try to identify the offers that result in scores at least as good as the current compromise simultaneously for both the negotiators. The results of the electronic negotiation experiments show that NSSs find the solutions better than the negotiated agreement for $65 \%$ of all cases (Wachowicz and Kersten 2009). The post-negotiation optimization capabilities of NSSs seem to be very important because they are giving the opportunity to improve the agreement and consume the gains left on negotiation table. The results of post-negotiation optimization conducted by eNS Inspire are shown in Fig. 9. 


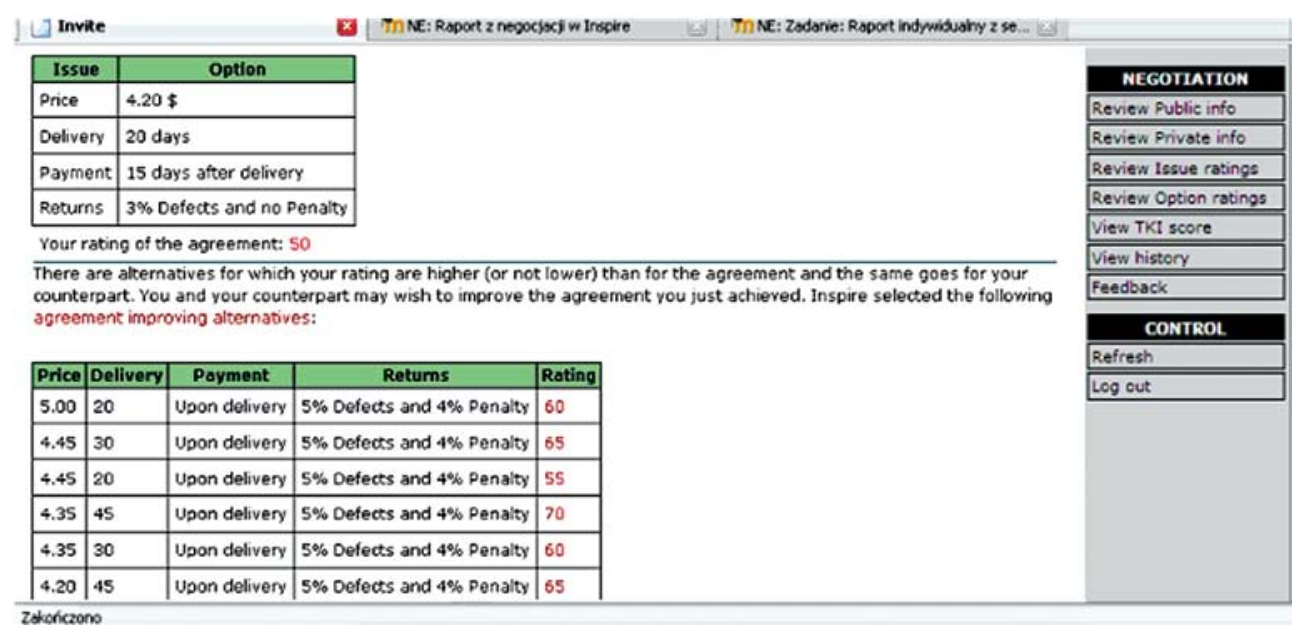

Fig. 9. Improvement of current agreement found by eNS Inspire

Knowing the scale of possible improvements negotiators can renegotiate the current agreement trying to move themselves to one of the solutions proposed by the system. But what is interesting, only $22 \%$ of negotiators that NSS suggested the improvements to, took an advantage of the renegotiation and improved their final score (Wachowicz and Kersten 2009). The rest of them decided to stay in the negotiated agreement claiming that the system proposals cannot be accepted (despite they resulted in higher score than an agreement) because these offers do not satisfy their reservation levels on some options. This explanation shows that negotiators reject sometimes the notion of compensation and the alternative scoring mechanisms, like the one based on calibrated ELECTRE-TRI, that should be implemented. However, there are yet no research works showing the post-negotiation capabilities of scoring systems based on ELECTRE-TRI or other outranking or sorting methods.

\section{Conclusions}

In this paper we discussed the problem of decision support that can be given in negotiations supported by negotiation support systems. This is a very interesting problem, since more and more negotiations are conducted in the electronic way and sooner or later negotiators will require professional tools that could efficiently help them in the conduct of negotiation. We described thus the structure of negotiation process and showed different possibilities of its support considering the role and activity NSSs can play. Then we tried to focus on the decision process that takes place in the pre-negotiation phase discussing the classical approach to eliciting preferences and building the offers' scoring system that was based on the additive scoring system with the utility payoffs. We tried to emphasize its simplicity showing also some disadvantages of it and proposing two alternative approaches. 
The first approach derived from Hammond, Keeney and Raiffa even-swap method also assumes full compensation on issues. The main difference in comparison with the utility based additive scoring system is the philosophy of defining the trade-offs. Here negotiators decide themselves what kind of units to use to express the overall score of offer. They select the base issue and try to evaluate all other options of all issues in terms of base one, using its units to define the equivalent amounts for swaps between issues.

The second approach rejects compensation and tries to build the scoring system using pseudo-criteria. This ELECTRE-TRI based model in conjunction with the MS model for estimation of key parameters can become a very helpful and simple to use supporting tool. Instead of asking negotiators to assign the scores it tries to derive the preferences basing on the assignment examples. This indirect approach does not force negotiators to score each negotiation option separately and declare the abstract values (i.e. utilities, desirabilities) to what they can sometimes perceive as immeasurable. It only asks to formulate the alternatives that negotiators can judge intuitively to be good, medium or bad and then, using some assumptions, tries to identify the profiles that limit these categories. To increase the precision of such an evaluation we decided to calibrate the scoring system using satisfaction scores assigned to the initial profiles of the categories. What is more, we decided to divide the categories into the sub-categories by simple interpolation between the values of the successive profiles, which allowed to distinguish the differences between two offers that were previously classified to the same category.

We also tried to show that the choice of scoring system has the consequences for the subsequent negotiation phases. The methods that can easily build the scoring system in the pre-negotiation phase deriving from the negotiators' decision or choices may not allow later for making any sophisticated analysis of the negotiation progress or the scale of concessions (i.e. the ELECTRE-TRI based scoring system).

The future work will focus on the implementation of the calibrated ELECTRE-TRI model to the electronic negotiation system and making the comparison study with the utility based scoring system that will show how the negotiators perceive a use and usefulness of these two different tools.

\section{Acknowledgements}

This work has been supported by Polish Ministry of Science and Higher Education, as a part of scientific project number N N111 234936.

\section{References}

Aaronson, K. 1989. Selling on the Fast Track. G. P. Putnam’s Sons, New York.

Bellucci, E.; Zeleznikow, J. 2005. Developing negotiation decision support systems that support mediators: a case study of the Family_Winner system, Artificial Intelligence and Law 13(2): 233- 271. doi:10.1007/s10506-006-9013-1

Brams, S. J. 1990. Negotiation games: applying game theory to bargaining and arbitration. Routledge, New York. doi:10.4324/9780203180426 
De Keyser, W.; Peeters, P. 1996. A note on the use of PROMETHEE multicriteria methods, European Journal of Operational Research 89(3): 457-461. doi:10.1016/0377-2217(94)00307-6 Douglas, A. 1962. Industrial peacemaking. Columbia University Press, New York.

Greenhalgh, L. 2001. Managing strategic relationship. Free Press, New York.

Gulliver, P. 1979. Disputes and Negotiations: A Cross-Cultural Perspective. Academic Press, New York.

Hammond, J. S.; Keeney, R. L.; Raiffa, H. 1998. Even swaps: A rational method for making trade-offs, Harvard Business Review 76(2): 137-149.

Hammond, J. S.; Keeney, R. L.; Raiffa, H. 2002. Smart Choices. A Practical Guide to Making Better Life Decisions. Broadway Books, New York.

Hordijk, L. 1991. Use of the RAINS model in acid rain negotiation in Europe, Environmental Science Technology 25(4): 596-603. doi:10.1021/es00016a002

Keeney, R. L.; Raiffa, H. 1976. Decisions with Multiple Objectives. Wiley, New York.

Keeney, R. L.; Raiffa, H. 1991. Structuring and Analyzing Values for Multiple-Issue Negotiations, in H. P. Young. Negotiation Analysis. The University of Michigan Press, 131-152.

Kersten, G. E. 2005. E-negotiation Systems: Interaction of People and Technologies to Resolve Conflicts, The Magnus Journal of Technology 1(3): 71-96.

Kersten, G. E.; Noronha, S. J. 1999. WWW-based negotiation support: design, implementation and use, Decision Support Systems 25(2): 135-154. doi:10.1016/S0167-9236(99)00012-3

Kersten, G. E.; Lai, H. 2007. Negotiation support and e-negotiation systems, Group Decision and Negotiation 16(6): 553-586. doi:10.1007/s10726-007-9095-5

Kuhn, R. 1999. How to Plan the Strategies, in Lewicki, R. J.; Saunders, D. M.; Minton, J. W. (Eds.). Negotiation. Reading, Exercises and Cases. Irwin/McGraw-Hill, Boston, 54-59.

Lai, H.; Lin, H. C.; Lin, W. J. 2007. NeGoGo: ANeGo and SynNeGo, in G. E. Kersten; J. Rios; E. Chen,, in Group Decision and Negotiation 2007: Proceedings. InterNeg Research Centre, Concordia University, Montreal, 75-81.

Lewicki, R. J.; Saunders, D. M.; Minton, J. W. 1999. Negotiation. Reading, Exercises and Cases. Irwin/McGraw-Hill, Boston.

Lewicki, R. J.; Saunders, D. M.; Barry, B.; Minton, J. W. 2004. Essentials of Negotiation. $3^{\text {rd }}$ Ed. Irwin/McGraw-Hill, New York.

Luce, R. D.; Raiffa, H. 1957. Games and Decisions. Wiley, New York.

Madrigal, D. O.; Bowman, D. R.; McClain, B. U. 2009. Introducing the Four-Phase Model of Hostage Negotiation, Journal of Police Crisis Negotiations 9(2): 119-133. doi:10.1080/15332580902865144

Morley, I.; Stephenson, G. 1977. The Social Psychology of Bargaining. Allen and Unwin, London.

Mousseau, V.; Slowinski, R. 1998. Inferring an ELECTRE TRI Model From Assignment Examples, Journal of Global Optimization 12(2): 157-174. doi:10.1023/A:1008210427517

Mustajoki, J.; Hamalainen, R. P. 2000. Web-HIPRE: global decision support by value tree and AHP analysis, INFOR 38(3): 208-220.

Raiffa, H. 1982. The Art and Science of Negotiation. Harvard University Press, Cambridge.

Raiffa, H.; Richardson, J.; Metcalfe, D. 2002. Negotiation Analysis. The Belknap Press of Harvard University Press, Cambridge. 
Roy, B.; Vincke, Ph. 1984. Relational systems of preferences with one or more pseudo-criteria: some new concepts and results, Management Science 30(11): 1323-1335.

doi: $10.1287 /$ mnsc.30.11.1323

Roy, B.; Bouyssou, D. 1993. Aide multicritère à la decision: Méthodes et cas, Economica, Paris.

Saaty, T. 2001. The Seven Pillars of the Analytic Hierarchy Process, in M. Köksalan; S. Zionts. Multiple Criteria Decision Making in the New Millennium. Springer-Verlag, Berlin, Heidelberg, 15-37.

Scott, B. 1999. Preparing for Negotiations, in R. J. Lewicki, D. M. Saunders, J. W. Minton. Negotiation. Reading, Exercises and Cases. Irwin/McGraw-Hill, Boston, 60-67.

Schoop, M.; Jertila, A.; List, T. 2003. Negoisst: a negotiation support system for electronic business-to-business negotiations in e-commerce, Data \& Knowledge Engineering 47(3): 371-401. doi:10.1016/S0169-023X(03)00065-X

Sebenius, J. K. 1984. Negotiating the Law of the Sea. Cambridge, MA, Harvard University Press. Stroebel, M.; Weinhardt, C. 2003. The Montreal Taxonomy for Electronic Negotiations, Group Decision and Negotiation 12: 143-164. doi:10.1023/A:1023072922126

Tafreschi, O.; Mähler, D.; Fengel, J., Rebstock, M.; Eckert, C. 2008. A reputation system for electronic negotiations, Computer Standards \& Interfaces 30: 351-360. doi:10.1016/j.csi.2008.03.003

Thiessen, E. M.; Shakun, M. F. 2009. First Nations Negotiations in Canada: Action research using Smartsettle, in M. Kilgour; Q. Wang. Proceedings of GDN 2009: an International Conference on Group Decision and Negotiation. Wilfried Laurier University: 171.

Thiessen, E. M.; Soberg, A. 2003. Smartsettle described with the montreal taxonomy, Group Decision and Negotiation 12(2): 165-170. doi:10.1023/A:1023025106197

Thompson, L. 1998. The Mind and Heart of the Negotiator. Prentice Hall, Uppers Saddle River.

Ulubeyli, S.; Kazaz, A. 2009. A multiple criteria decision-making approach to the selection of concrete pumps, Journal of Civil Engineering and Management 15(4): 369-376.

doi:10.3846/1392-3730.2009.15.369-376

Urbanavičienė, V.; Kaklauskas, A.; Zavadskas, E. K.; Seniut, M. 2009a. The web-based real estate multiple criteria negotiation decision support system: a new generation of decision support systems, International Journal of Strategic Property Management 13(3): 267-286. doi:10.3846/1648-715X.2009.13.267-286

Urbanavičienė, V.; Kaklauskas, A.; Zavadskas, E. K. 2009b. The conceptual model of construction and real estate negotiation, International Journal of Strategic Property Management 13(1): 53-70. doi:10.3846/1648-715X.2009.13.53-70

Ustinovichius, L.; Barvidas, A.; Vishnevskaja, A.; Ashikhmin, I. 2009. Multicriteria verbal analysis for the decision of construction problems, Technological and Economic Development of Economy 15(2): 326-340. doi:10.3846/1392-8619.2009.15.326-340

Wachowicz, T. 2007. Even Swaps Method for Developing Assessment Capabilities of E-Negotiation System, in M. Ganzha, M. Paprzycki, T. Pełech-Pilichowski. Proceedings of the International Multiconference on Computer Science and Information Technology, Vol. 2, Polish Information Processing Society, 597-606.

Wachowicz, T. 2008. NegoCalc: Spreadsheet Based Negotiation Support Tool with Even-Swap Analysis, in J. Climaco, G. Kersten, J. P. Costa. Group Decision and Negotiation 2008: Proceedings - Full Papers. INESC Coimbra, 323-329.

Wachowicz, T.; Kersten, G. E. 2009. Zachowania i decyzje negocjacyjne uczestników negocjacji elektronicznych [Decisions And Manners Of Electronic Negotiation System Users], in K. A. Kłosiński, A. Biela. Proceedings of an International Scientific Conference "A Man And His Decisions”. John Paul II Catholic University of Lublin Press, 63-74. 
Wachowicz, T.; Wieszała, P. 2009. Pre-Negotiation Phase Protocol For Electronic Negotiation Support, in L. Zadnik Stirn, J. Zerovnik, S. Drobne, A. Lisec. SOR'09 Proceedings. Slovenian Society Informatika - Section of Operations Research, Ljubljana, 185-194.

Young, H. P. 1991. Negotiation Analysis, in H. P. Young. Negotiation Analysis. The University of Michigan Press, 1-23.

Zeckhauser, R. J.; Keeney, R. L.; Sebenius, J. K. 1996. Wise Choices. Decision, Games and Negotiations. Harvard Business School Press, Boston, Massachusetts.

\section{DERYBŲ SPRENDIMŲ PARAMOS PROGRAMA}

\section{T. Wachowicz}

\section{Santrauka}

Straipsnyje pateikiama idejja apie derybų vykdymą naudojantis sprendimų paramos programa. Pristatomi derybų sistemos privalumai aptariant skirtingas funkcijas ir tipologijas, vèliau akcentuojant sprendimų paramos sistemos galimybes, kurias gali duoti ši sistema kiekvienai iš derybų šaliu bet kuriuo derybu etapu. Pristačius populiariausius sprendimus pateikiamos dvi procedūros, kurios gali būti taikomos norint išsiaiškinti derybininko prioritetus ir sudaryti siūlančio asmens šalių vertinimo sistemą. Pirmoji paremta Hammond, Keeney and Raiffa lygių mainų procedūra, o antroji - Roy sukurta ELECTRE-TRI. Šios procedūros gali būti lengvai pritaikytos kaip analitinė sistema elektroninèje derybų sistemoje, pakeičiant klasikines adityviąsias vertinimo sistemas. Nagrinèjama, kaip skirtingos vertinimo sistemos naudojamos tolesniuose derybų etapuose.

Reikšminiai žodžiai: derybos, sprendimų paramos sistemos, sprendimo analizė, daugiakriterinis vertinimas, lygūs mainai, ELECTRE-TRI.

Tomasz WACHOWICZ. Graduated in 1999 from the Karol Adamiecki University of Economics in Katowice (Poland) with a degree in management science. He was employed as an analyst in the Advertising Agency of Polish National Radio in Katowice. In 2000 he joined a PhD program at the Karol Adamiecki University of Economics and obtained his $\mathrm{PhD}$ in 2004 with the thesis entitled: "Quantitative Methods In Modeling The Business-to-Business Negotiation". Since 2005 he has been employed in the Department of Operations Research at the Karol Adamiecki University of Economics in Katowice.

The main focus of his research is the negotiation analysis. He is the author of scientific papers on negotiation support, negotiation support systems, multiple criteria decision making, game theory and project management. He participated in international scientific projects, such as „Electronic Negotiation, Media And Transactions For Socio-Economic Interactions” (2003) organized by University of Ottawa, or “Global Research In INSPIRE Negotiations” (2009) organized by InterNeg Research Centre and also took part in a few scientific projects founded by the Polish Ministry of Science and Higher Education (PMSHE) and nowadays he leads a three-year research project "Preference Analysis and Support of the Negotiators“ supported by PMSHE. He cooperates with international research centers and universities such as InterNeg research Centre (Montreal), Vienna University of Technology (Austria), University of Economics in Prague (Czech Republic) and University of Malaga (Spain). He has been the head of organizing committee of the cyclical national conference "Preference Modeling Versus Risk" and "International Workshop on Multiple Criteria Decision Making” (www.iwomcdm.ae.katowice.pl). He is also a member of the International Society on Multiple Criteria Decision Making and EURO Working Group on Multi-Criteria Decision Aiding. 